\title{
Parametric investigation of a non-constant cross sectional area air to air heat exchanger
}

\author{
Author: Bruno Cárdenas * A \\ Bruno.Cardenas@nottingham.ac.uk \\ Tel : +44 1159513811 \\ Co-Author: Bharath Kantharaj ${ }^{A}$ \\ Bharath.Kantharaj@nottingham.ac.uk
}

\author{
Co-Author: Seamus Garvey ${ }^{A}$ \\ Seamus.Garvey@nottingham.ac.uk \\ Tel: +44 1159513776 \\ Co-Author: Michael Simpson ${ }^{A}$ \\ Michael.Simpson@nottingham.ac.uk
}

Affiliation:

A University of Nottingham, Department of Mechanical, Materials and Manufacturing Engineering University Park, NG7 2RD, Nottingham, United Kingdom

* Corresponding Author

5

6

\begin{abstract}
The present article addresses the design, mathematical modelling and analysis of a novel highly exergyefficient air to air heat exchanger. An intricate design based on an hexagonal mesh is proposed for the crosssectional area of the heat exchanger with aims to explore the performance gains that can be obtained by exploiting the capabilities and benefits offered by modern fabrication techniques such as additive manufacturing. Special attention is paid to understanding the relationship or trade-off that exists between the overall exergy efficiency of the heat exchanger and its cost.

The iterative algorithm used to find the geometrical parameters that yield the best performance in terms of volume of material required per unit of exergy transfer at a certain level of efficiency, as well as the assumptions and simplifications made, are comprehensively explained.

It has been found through the analyses carried out performed, which are thoroughly discussed throughout the paper, that if the characteristic dimension of the heat exchanger is scaled up by a factor of $n$, the volume of material per kW of exergy transfer at certain exergy efficiency will increase by a factor of $n$ squared. This is a very important observation, possibly applicable to other types of heat exchangers, that indicates that performance improves dramatically at smaller scales.

The overall performance of the case study presented is satisfactory, a volume of material as low as $84.8 \mathrm{~cm}^{3}$ for one kW of exergy transfer can be achieved with a $99 \%$ exergy efficiency.
\end{abstract}

\section{Keywords}

Gas to gas heat exchanger; high exergy efficiency heat exchanger; non-constant cross sectional area; heat exchanger additive manufacturing; heat exchanger cost optimization

\section{Table of Contents}

1. Introduction

2. Geometric design of the air to air heat exchanger

3. Mathematical modelling of a segment of the HX

4. Analysis of results obtained for an $\mathrm{HX}$ segment

4.1 Fine tuning of slow moving variables

5. Concluding Remarks

6. References 


\begin{tabular}{|c|c|c|c|}
\hline \multicolumn{4}{|c|}{ Nomenclature } \\
\hline \multicolumn{2}{|c|}{ Acronyms } & $n$ & number of rings of HP pipes \\
\hline$H P$ & High Pressure & $N u$ & Nusselt number \\
\hline$H X$ & Heat Exchanger & $\varnothing$ & Pipe diameter $(\mathrm{m})$ \\
\hline$L P$ & Low Pressure & $\emptyset_{h}$ & Hydraulic pipe diameter $(\mathrm{m})$ \\
\hline \multicolumn{2}{|c|}{ Symbology } & $\psi$ & Fraction of the pipe being analysed \\
\hline$A$ & Cross sectional area $\left(\mathrm{m}^{2}\right)$ & $p$ & Perimeter of flow area of pipe (m) \\
\hline$A_{r}$ & Ratio of cross sectional areas HP/LP & $P$ & Pressure $(\mathrm{Pa})$ \\
\hline $\bar{B}$ & Mean exergy transfer $(\mathrm{W} / \mathrm{m})$ & $P_{H P}$ & Pressure of the HP side (Pa) \\
\hline$B_{H P}$ & Exergy of the heat at the HP side $(\mathrm{W} / \mathrm{m})$ & $P_{L P}$ & Pressure of the LP side $(\mathrm{Pa})$ \\
\hline$B_{L P}$ & Exergy of the heat at the LP side $(\mathrm{W} / \mathrm{m})$ & $\operatorname{Pr}$ & Prandtl number \\
\hline$B_{\text {LOSS }}$ & Total exergy losses $(\mathrm{W} / \mathrm{m})$ & $\dot{Q}$ & Heat transfer rate per unit length $(\mathrm{W} / \mathrm{m})$ \\
\hline$B_{L Q}$ & Exergy loss due to heat transfer $(\mathrm{W} / \mathrm{m})$ & $\rho$ & Density of air $\left(\mathrm{kg} / \mathrm{m}^{3}\right)$ \\
\hline$B_{\Delta P}$ & Exergy loss due to pressure drop $(\mathrm{W} / \mathrm{m})$ & $r_{H P}$ & Radius of the HP pipe (m) \\
\hline$B_{\triangle H P}$ & $\begin{array}{l}\text { Exergy loss due to pressure drop in the HP } \\
\text { side }(\mathrm{W} / \mathrm{m})\end{array}$ & $R e$ & Reynolds number \\
\hline$B_{\triangle L P}$ & $\begin{array}{l}\text { Exergy loss due to pressure drop in the LP } \\
\text { side }(\mathrm{W} / \mathrm{m})\end{array}$ & $S$ & Allowable stress of pipe material (Pa) \\
\hline$C_{P}$ & Specific heat capacity (J/kg K) & $t_{H P}$ & Thickness of HP pipes (m) \\
\hline$\Delta P$ & Pressure drop per unit length $(\mathrm{Pa} / \mathrm{m})$ & $t_{L P}$ & Thickness of the flange at the base $(\mathrm{m})$ \\
\hline$\Delta P_{H P}$ & Pressure drop in the HP side $(\mathrm{Pa} / \mathrm{m})$ & $t_{m f}$ & Thickness of the flange at midpoint (m) \\
\hline$\Delta P_{L P}$ & Pressure drop in the LP side $(\mathrm{Pa} / \mathrm{m})$ & $T_{a m b}$ & Ambient temperature $(\mathrm{K})$ \\
\hline$\Delta T$ & Temperature delta from $T_{a v g}(\mathrm{~K})$ & $T_{\text {avg }}$ & Average temperature of $\mathrm{HX}$ section $(\mathrm{K})$ \\
\hline$D$ & Distance between centres of HP pipes (m) & $T_{H P}$ & Temperature of the HP stream (K) \\
\hline$\varepsilon$ & Roughness height (m) & $T_{i}$ & Temperature of inner wall of HP pipe (K) \\
\hline$\varepsilon / \varnothing$ & Relative pipe roughness & $T_{L P}$ & Temperature of the LP stream $(\mathrm{K})$ \\
\hline$f_{D}$ & Darcy-Weisbach friction factor & $T_{m f}$ & Temperature of the flange at middle $(\mathrm{m})$ \\
\hline$h$ & Convection coefficient $\left(\mathrm{W} / \mathrm{m}^{2} \mathrm{~K}\right)$ & $T_{O}$ & Temperature of outer wall of HP pipe (K) \\
\hline$k_{\text {air }}$ & Thermal conductivity of air (W/m K) & $T(x)$ & Temperature at a point $\mathrm{x}$ in flange $(\mathrm{K})$ \\
\hline$k_{\text {wall }}$ & Thermal conductivity of wall (W/m k) & $\nabla T$ & Temperature gradient of $\mathrm{HX}$ segment $(\mathrm{K} / \mathrm{m})$ \\
\hline$\lambda$ & $\begin{array}{l}\text { Fraction of HP pipe perimeter covered by } \\
\text { flanges }\end{array}$ & $U$ & Mean flow velocity of air (m/s) \\
\hline$L$ & Height of the flange $(\mathrm{m})$ & $V / \bar{B}$ & $\begin{array}{l}\text { Volume of material per unit exergy transfer } \\
\left(\mathrm{m}^{3} / \mathrm{kW}\right)\end{array}$ \\
\hline$\mu$ & Dynamic viscosity of air ( $\mathrm{Pa} \mathrm{s}$ ) & $W$ & Exergy efficiency \\
\hline$\dot{m}_{H P}$ & Mass flow rate per HP pipe $(\mathrm{kg} / \mathrm{s})$ & $X$ & Ratio of proportional pressure drops \\
\hline$\dot{m}_{L P}$ & Mass flow rate per LP pipe $(\mathrm{kg} / \mathrm{s})$ & $Y$ & Ratio of temperature differences \\
\hline$m m$ & Flange performance factor & $Z$ & $\begin{array}{l}\text { Fraction of total exergy losses caused by } \\
\text { pressure drops }\end{array}$ \\
\hline
\end{tabular}

1

\section{1. Introduction}

3 Heat exchangers $(\mathrm{HX})$ are devices that allow the transfer of thermal energy between two or more streams of

4 fluids at different temperatures. Nowadays they are employed for countless industrial processes. Several

5 different types of heat exchangers have been developed for different applications; being the Shell and Tube

6 (STHX) and Plate-Fin (PFHX) two of the most widely used configurations [1].

8 The design of a $\mathrm{HX}$ is far from being a trivial task as it involves a number of highly interdependent geometric

9 and operating variables that often pose technical contradictions (or trade-offs) [2]; however, through a careful

10 selection of design parameters a highly efficient and cost-effective design can be realised, which is of growing

11 importance for the industry given their extensive utilization in a multitude of processes. 
Considerable amount of research has been devoted in the past years to develop design strategies that allow achieving significant cost reductions in the design of a heat exchanger for a specific heat duty. Various researchers have resorted to the use of evolutionary algorithms and other population-based optimization methods with objective functions aimed at minimizing the total cost due to their ability to handle the large amount of design parameters [3].

Sanaye and Hajabdollahi carried out a multi-objective (cost and effectiveness) optimization of a shell and tube heat exchanger [4] and a plate fin heat exchanger [5] through a genetic algorithm. In both cases the authors presented a set of multiple optimum solutions due to the conflict between the two objective functions. Hajabollahi et al. [6] presented a multi-objective (maximum effectiveness and minimum pressure drop) optimization of a compact PFHX done by means of a genetic algorithm. The study reveals that any geometrical changes which decrease the pressure drop in the optimum situation, lead to a decrease in the effectiveness and vice versa, therefore a set of multiple optimum solutions is presented.

Najafi et al. [7] optimized the design of a PFHX in terms of total rate of heat transfer and the total annual cost of the system through a genetic algorithm. They provide a wide range of optimal solutions, each of which is a trade-off between the highest total rate of heat transfer and the least total annual cost. Fetakka et al. [8] carried out, through a genetic algorithm, a multi-objective optimization of two different STHX trying to minimize simultaneously heat transfer area and pumping power. The authors report, for both case studies, better values for the two objective functions and for the cost of the different optimal designs in comparison to the values previously reported in the literature.

Patel and Rao [9] applied a particle swarm optimization (PSO) algorithm for minimizing the total annual cost of a STHX. The four different case studies presented demonstrate the effectiveness and accuracy of the proposed algorithm. Rao and Patel [10] repeated the study with a PFHX, in which two case studies were analysed. An improvement was observed over the results obtained through genetic algorithms by previous researchers. Mariani et al. [11] used a quantum PSO method for optimizing the design of a STHX. The authors presented two case studies in which significant cost reductions, a $20 \%$ reduction of capital investment and a $72 \%$ reduction in the annual pumping cost are observed. Furthermore, the results of the two case studies using the quantum PSO are compared with those obtained by genetic algorithms and classic particle swarm showing the superiority of quantum PSO.

Sadeghzadeh et al. [12] carried out a comparison between a genetic algorithm and a particle swarm algorithm for the techno-economic optimization of a STHX. The objective function to minimize is a cost function containing costs of the heat exchanger based on surface area and power consumption to overcome pressure drops. It was found, in agreement with Mariani et al. [11], that results obtained with the particle swarm optimization method are superior to those obtained with the genetic algorithm method. Turgut [13] investigated the utilization of a hybrid chaotic quantum PSO algorithm for the optimization of PFHX in terms of minimizing the heat transfer area, total pressure drop and total cost for a specified heat duty. It was observed that the proposed algorithm converged successfully to an optimum configuration with a higher accuracy than many other optimization algorithms discussed in the literature.

Hadidi et al. [14] presented the optimization of the design of a STHX, in terms of total cost of equipment, through an imperialist competitive algorithm. Reductions of capital investment up to $6.1 \%$ and savings in operating costs up to $94 \%$ were obtained with respect to the literature test cases. Yousefi et al. [15] explored the use of an improved harmony search algorithm to optimize the design of a PFHX. Numerical results for the two case studies evaluated (minimizing heat transfer area and minimizing pressure drops) indicate that the approach analysed can generate optimum solutions with higher accuracy when compared to genetic algorithms, PSO and hybrids between them. 
Wang and Li [16] applied an improved cuckoo search algorithm (CSA) for the multi-objective optimization of the design of a PFHX. The objective functions are the maximization of efficiency and minimization of pumping power and total annual cost. The algorithm employed proved to be able to obtain optimum solutions with higher accuracy and fewer iterations in comparison to single-objective design approaches. Asadi et al. [17] presented the minimization of the total annual costs (including the capital investment and operating expenses) of a STHX by means of a cuckoo search algorithm. Two case studies show that investment costs can be reduced by $9.4 \%$ and $13.1 \%$ compared to the results obtained from genetic algorithms and PSO, respectively.

Hultmann et al. [18] presented the optimization of both, a STHX and a PFHX, with a novel multi-objective free search-differential evolution algorithm. Results from the two multi-objective case studies using the proposed algorithm are compared with those obtained by genetic algorithms from which it is concluded that the free search -differential evolution algorithm presented outperforms the GA. Şahin et al. [19] applied an artificial bee colony $(A B C)$ algorithm to minimize the total cost of the equipment. Successful results were obtained for all case studies carried out. The authors report that the $A B C$ method is quicker and more accurate than traditional methods.

Hadidi and Nazari [2] applied a biogeography-based optimization (BBO) algorithm for minimizing the total cost of the equipment. A reduction in capital investment of up to $14 \%$ and savings in operating costs up to $96 \%$ with respect to the literature test cases were obtained. Rao and Patel [20] and Patel and Savsani [21] carried out a multi-objective optimization (effectiveness and total cost) of a PFHX and a STHX with a modified version of the teaching- learning algorithm. In both cases, a set of optimal solutions, each of which is a trade-off between the conflicting objectives, is provided. The researchers report better results than those produced by genetic algorithms for a similar problem.

Mohanty [22] explored the use of a firefly algorithm to carry out the economic optimization of a STHX. Two case studies were assessed, the results of which show that the total heat exchanger area can be reduced by $27.4 \%$ while the total cost can be reduced by $29 \%$ in comparison to the reference designs. Moreover, a comparison of the firefly algorithm against various design optimization algorithms such as $G A, P S O, A B C, B B O$ and CSA indicates that the firefly algorithm is the most effective method for optimizing the design of a STHX from an economic point of view.

As it can be seen, extensive research has been undertaken in the field of heat exchangers aimed at reducing the total cost of the equipment. Several researchers have studied in recent years different optimization algorithms capable of delivering good results.

All the aforementioned optimization techniques attain sizeable cost reductions notwithstanding being bound to a pre-conceived design which restricts their output. The heat exchangers that are currently utilised were designed decades ago under the restrictions imposed by the manufacturing techniques available at those times; however, there is a much broader spectrum of fabrication methods nowadays, such as additive manufacturing, that allow for much more intricate designs to be built, through which higher efficiencies and/or lower costs may be achieved. Therefore, research efforts should focus on generating designs of HX that depart from the existing ones and exploit to a higher degree the capabilities and benefits offered by modern manufacturing methods.

Accordingly, the present work explores an innovative geometry, which would be highly impractical to manufacture by traditional methods, for an air to air heat exchanger with the objective of generating designs that simultaneously maximize the exergy efficiency and minimize cost. The study pays special attention at thoroughly understanding the relationship or trade-off that exists between the overall exergy efficiency of HXs and their cost. 


\section{Geometric design of the air to air heat exchanger}

Typically, heat exchangers have a constant design (cross-sectional area) throughout their whole length; however this is not necessarily the best practice. It would be much more appropriate to have a HX with graded properties. Consequently, the approach proposed in the present work for finding the optimum geometry, in terms of maximum efficiency and minimum cost, is to design a HX with a non-constant cross-sectional area between the hot and cold ends. The length of the heat exchanger is divided into $n$ segments, as illustrated by Figure 1, and each segment is designed specifically for the temperature range at which it will operate.

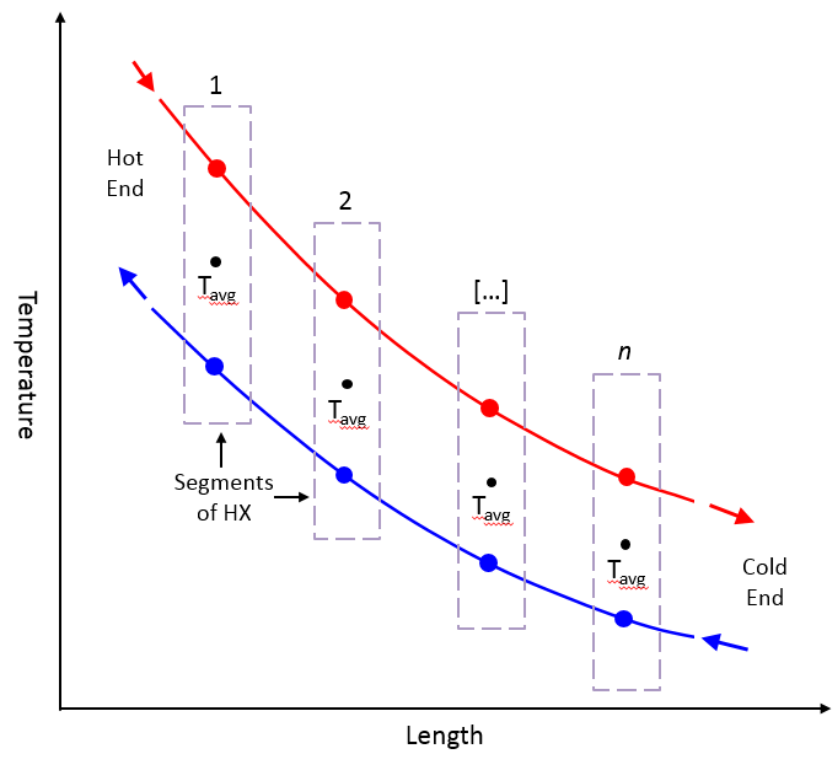

Figure 1. Length of a counter flow HX divided into $n$ segments

The body of the heat Exchanger can be regarded thus as series of segments or "slices" whose dimensions adjust with length. Each segment has a constant cross-section throughout its length (which should relatively small) however, geometric parameters change from one segment to the next. Therefore, the properties of the $\mathrm{HX}$ as a whole are modified in discrete steps rather than varying continuously with length; although there is no reason a priori why the latter could not be the case.

The cross-sectional area of each of the segments of the air to air heat exchanger is based on an hexagonal mesh (honeycomb pattern). This geometry was selected because it is a repeating pattern with multiple axes of symmetry, which offers the benefit of analysing only a very small section of it and assuming that the same behaviour will be observed elsewhere.

The low pressure (LP) and high pressure (HP) pipes are arranged in such a way that each HP pipe is surrounded by six LP pipes while each LP pipe is surrounded by three HP pipes. The cross-sectional area starts as a fully hexagonal mesh; then the HP pipes are transformed into circles and shrunk by some amount; because as it is known, a cylinder is the best geometric shape for pipes that will handle pressurized fluids. The outer walls of the HP pipes could remain straight having a cylindrical cavity on the inside, to maintain the structure of the hexagonal mesh; however this does not make an efficient use of the material. Consequently, the sides of the LP pipes, which are the remaining hexagons, have to be elongated by some amount.

Figure 2 shows the distribution of HP and LP pipes within the modified hexagonal mesh. The arrows indicate the interactions (heat flows) assumed for the modelling. As it can be seen, each HP pipe supplies heat to the six adjacent LP pipes while each LP pipe receives heat from the three HP pipes surrounding it. It is assumed that no thermal interaction occurs between neighbouring LP pipes. 


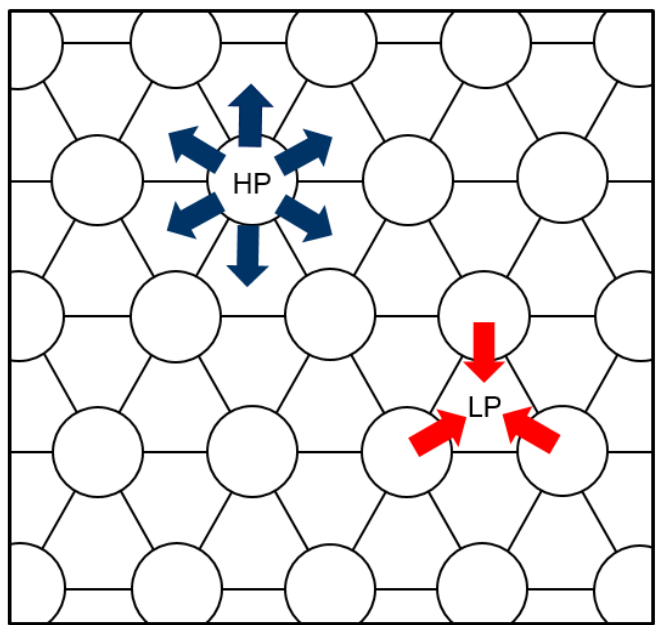

Figure 2. Interaction between HP and LP pipes in the hexagonal mesh

A notable characteristic of the geometry chosen is that it grows in concentric rings, as illustrated by Figure 3 . This feature allows adding more rings of HP pipes at the outer border of the cross section to increase the capacity of the HX without modifying its behaviour. Equations (1) and (2) account for the number of HP and LP pipes in the arrangement, respectively, according to the number of rings $(n)$. For a large number of rings there are approximately two LP pipes per each HP pipe in the geometry.

$$
H P=1+\sum_{i=1}^{n} 6 i
$$

$$
L P=\sum_{i=1}^{n} 6(2 i-1)
$$

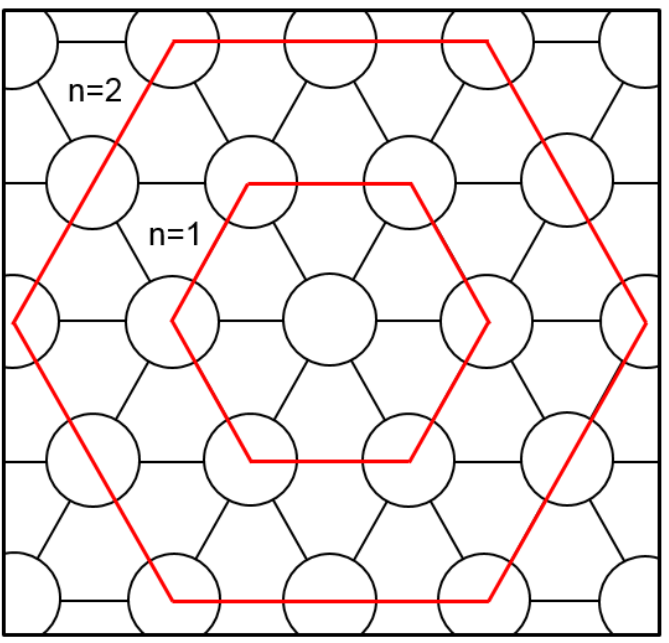

Figure 3. Arrangement of HP pipes in concentric rings within the hexagonal mesh

A section of the full geometry consisting of three HP pipes and the LP pipe comprised between them is shown in Figure 4. As it can be observed, the walls of the LP pipe are made by trapezoidal elements, referred to as "flanges" hereafter. In the envisioned applications for an air to air HX of this kind the LP stream is at ambient (or marginally higher) pressure; therefore there is not a minimum thickness requirement for the flanges in order to withstand pressure. Although the thinnest practical element is desired, the flanges need to be thick enough to be able hold the structure of the $\mathrm{HX}$ together and to transport heat from the wall of the HP pipe to the LP stream; that is to say, their sizing is governed by conduction rather than by pressure. 


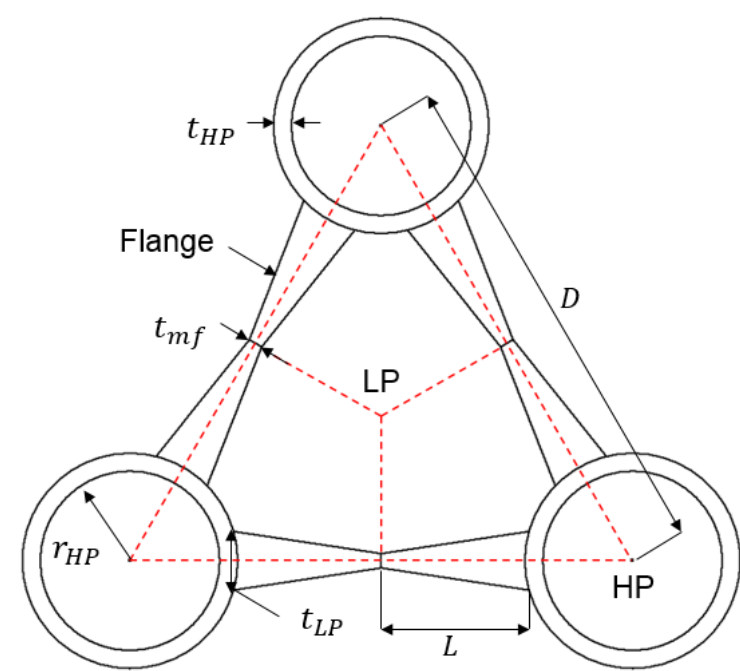

Figure 4. Section of the geometry consisting of an LP pipe and its 3 adjacent HP pipes

The geometry is defined, as it can be seen in Figure 4, by five parameters: The distance between centres of HP pipes $(D)$, the radius $\left(r_{H P}\right)$ and thickness $\left(t_{H P}\right)$ of the HP pipes, the thickness of the flange at its base $\left(t_{L P}\right)$ and the thickness of the flange at middle height $\left(t_{m f}\right)$. With the purpose of simplifying the problem to some extent, a pragmatic view regarding how thin the flange can be has been taken; a ratio of five to one was defined, i.e. the thickness of the flange at middle height is $20 \%$ of the thickness at the base.

\section{Mathematical modelling of a segment of the HX}

As earlier mentioned, the objective is to generate an optimum design in terms of cost per unit of exergy transfer, for the cross-sectional area of a specific segment of a HX for the temperature range at which it will operate. One of the main contributors to cost in an additive manufacturing process is the cost of the material utilized; therefore achieving reductions in the effective volume of the design is a very good approach for minimizing the total cost of the component.

The mathematical model and algorithm developed, which will be introduced and discussed in depth ahead, focus on the design and optimization of only 1 segment of the HX. The optimization of the whole body of a HX can be done on piecewise basis by applying the same algorithm to each one of the segments in the structure and optimizing them for their corresponding operating temperature range.

It results evident from Figure 4 that the solution is contained within a multidimensional space. An exhaustive search based on testing out every possible combination of variables to find the optimum design is certainly not a good approach because a large fraction of them will fail to meet the performance requirement or that may be physically unrealisable. Therefore, an organized approach to explore the multidimensional space is required.

In order to trace a better route to the solution, four additional variables named: $W, X, Y$ and $Z$ are introduced. Despite the fact that adding more variables to an already big array of parameters may seem counterintuitive, the new variables help to constrain the multidimensional space by relating two or more performance parameters of the $\mathrm{HX}$ segment between them. It is important to highlight that the aforementioned variables characterize the segment of $\mathrm{HX}$ and have a physical significance rather than just being an artificial means of constraining the design. The newly introduced variables are defined as follows:

- $\quad W$ is the required exergy efficiency from the HX segment. In this study efficiencies in the range of 97$99 \%$ are considered. This parameter defines indirectly the average temperatures of the HP and LP streams, as it will be explained later on. 
$44 \quad B_{L P}=\dot{Q} \cdot\left(1-\frac{T_{a m b}}{T_{a v g}-\Delta T}\right)$ structures total exergy losses.

$X=\frac{\left(\Delta P_{H P} / P_{H P}\right)}{\left(\Delta P_{L P} / P_{L P}\right)}$

$$
Y=\frac{T_{m f}-T_{L P}}{T_{O}-T_{L P}}
$$

$$
Z=\frac{B_{\triangle H P}+B_{\triangle L P}}{B_{L O S S}}
$$
exergy transfer. that equation (5) is satisfied.

- $\quad X$, given by Equation (3), is the ratio of proportional pressure drops $(\Delta P)$ between the two air streams.

- $\mathrm{Y}$, given by Equation (4), is a factor that describes the temperature drop along the flanges of the

- Z, given by Equation (5), is the ratio of the exergy losses due to pressure drops with respect to the

The four aforementioned variables are referred to as "slow moving" variables because their value changes little in comparison with the rest of the (fast moving) variables in the space such as $D, r_{H P}, t_{L P}$ and $\dot{m}$, which means that it is possible to define their value arbitrarily and still approximate a good solution. Thus for any choice of these, the remaining fast moving variables are investigated. The values of the slow moving variables can be subsequently fine-tuned to achieve a further reduction in the volume of material required per unit of

A challenge encountered within the present study is that all the variables are highly interdependent between them; which makes it necessary to implement an iterative process to search for the solution.

Figure 5 shows schematically the calculation process followed by the algorithm developed. The algorithm relies on three iterative loops, one that determines the radius and wall thickness of the HP pipes so that the proportional pressure drops meet Equation (3), a second one that determines the thickness of the flanges based on Equation (4) and a third one that encompasses the previous two and adjusts the mass flow rates so

\section{$<$ Attached at the end of document $>$}

\section{Figure 5. Algorithm for the calculations}

The distance between centres of HP pipes is the fast moving variable that is used as the characteristic dimension. Different designs are generated for a number of different values of $D$ and compared between them to find the best performing configuration. An initial set of parameters has to be provided to the algorithm before any calculations are performed; this set includes:

- The average temperature at which the $\mathrm{HX}$ segment will be operating $\left(T_{a v g}\right)$

- The pressure of the HP and LP air streams $\left(P_{H P}\right.$ and $\left.P_{L P}\right)$

- Properties of the material of the construction: thermal conductivity $\left(k_{\text {wall }}\right)$ and allowable stress $(S)$

After the initial parameters, the values of the slow moving variables $W, X, Y$ and $Z$ are defined, as well as the $D$ for which a design will be generated. The temperatures of the HP and LP fluids are calculated from $W, Z$ and $T_{\text {avg }}$ through the following set of equations: 
$B_{H P}=\dot{Q} \cdot\left(1-\frac{T_{a m b}}{T_{a v g}+\Delta T}\right)$

$3 \bar{B}=\frac{B_{L P}+B_{H P}}{2}$

$4 \quad(1-W) \cdot(1-Z)=\frac{B_{H P}-B_{L P}}{\bar{B}}$

$T_{H P}=T_{a v g}+\Delta T$

$T_{L P}=T_{\text {avg }}-\Delta T$

The calculations begin by making a guess for the mass flow rates. From an engineering point of view it is very convenient to have equal mass flow rates on both directions of the HX; so the $\dot{m}_{H P}$ is twice as much as the $\dot{m}_{L P}$ because there are twice as many LP pipes as HP pipes. It is also important to highlight that performance parameters in the calculations are expressed per unit length, as the length of the segment of $\mathrm{HX}$ (as well as the whole $\mathrm{HX}$ ) is left purposely undefined.

The first iterative loop of the algorithm, as aforementioned, determines the radius of the HP pipe $\left(r_{H P}\right)$ so that the ratio between the proportional pressure drops of both streams satisfy Equation (3) for the $X$ defined. For clarity, a value of 1 for $X$ means that the proportional pressure drops of both streams are equivalent while if $X$ $>1$ the proportional pressure losses in the HP stream are greater than in the LP stream. First, a guess for $r_{H P}$ is made; based on this value, the pressure drops per unit length inside the pipes are calculated via the DarcyWeisbach equation (12) [23]. The friction factor $\left(f_{D}\right)$ is calculated through the Haaland equation (13), which is an approximation to the iterative Colebrook equation [24]. The accuracy of the friction factor obtained from this equation has an error margin of $\pm 2 \%$ for Reynolds numbers greater than 3000 [25].

$\Delta P=f_{D} \cdot \frac{\rho}{2} \cdot \frac{U^{2}}{\emptyset}$

$f_{D}^{-1 / 2}=-1.8 \cdot \log _{10} \cdot\left[\left(\frac{\varepsilon / \emptyset}{3.7}\right)^{1.1}+\frac{6.9}{R e}\right]$

28

29

30

The case of the HP stream is calculated first. At this point $t_{H P}$ is also determined, by means of Barlow's equation (14). The thickness of the pipe depends on the pressure of the fluid and of course on the allowable stress (S) of the material [26]. The pipe cannot be thinner because it would burst, and it shouldn't be thicker because adding more material hurts performance. It should be mentioned that the allowable stress is a fixed value defined at the beginning of the calculations, therefore the optimization algorithm cannot generate designs that do not have a wall thick enough to hold the pressure of the HP stream.

$t_{H P}=\frac{P_{H P} \cdot r_{H P}}{S-P_{H P}}$

Thereafter the pressure drop on the LP side is calculated. Given that the cross sectional area of the LP pipe is not circular, the hydraulic diameter has to be calculated [27], by means of Equation (15), before the DarcyWeisbach equation can be applied.

$\emptyset_{h}=4 A / p$

The value of $r_{H P}$ is updated and the calculations repeated until the values obtained for the proportional pressure drops on both sides satisfy the Equation (3). Subsequently, the second iterative loop of the algorithm calculates the appropriate thickness of the flanges. This is done through a double iteration with $T_{O}$, which is the temperature of the outer wall of the HP pipe, and $t_{L P}$, which is the thickness of the base of the flange. 
Guesses are made for both variables and a $T_{m f}$ is found such that Equation (4) is satisfied for the defined value of $Y$. The flange is assumed to have a temperature gradient described by the Equation (16) [28]. Figure 6 shows graphically the temperature profile along the longitudinal axis of the flange.

$5 \quad T(x)=\frac{\left(T_{O}-T_{L P}\right) \cdot \cosh (m m *(L-x))}{\cosh (m m * L)}+T_{L P}$

6

Where:

$m m=L^{-1} \cdot\left(\cosh ^{-1}(1 / Y)\right)$

$L=0.5 \cdot\left(D-2\left(r+t_{H P}\right)\right)$

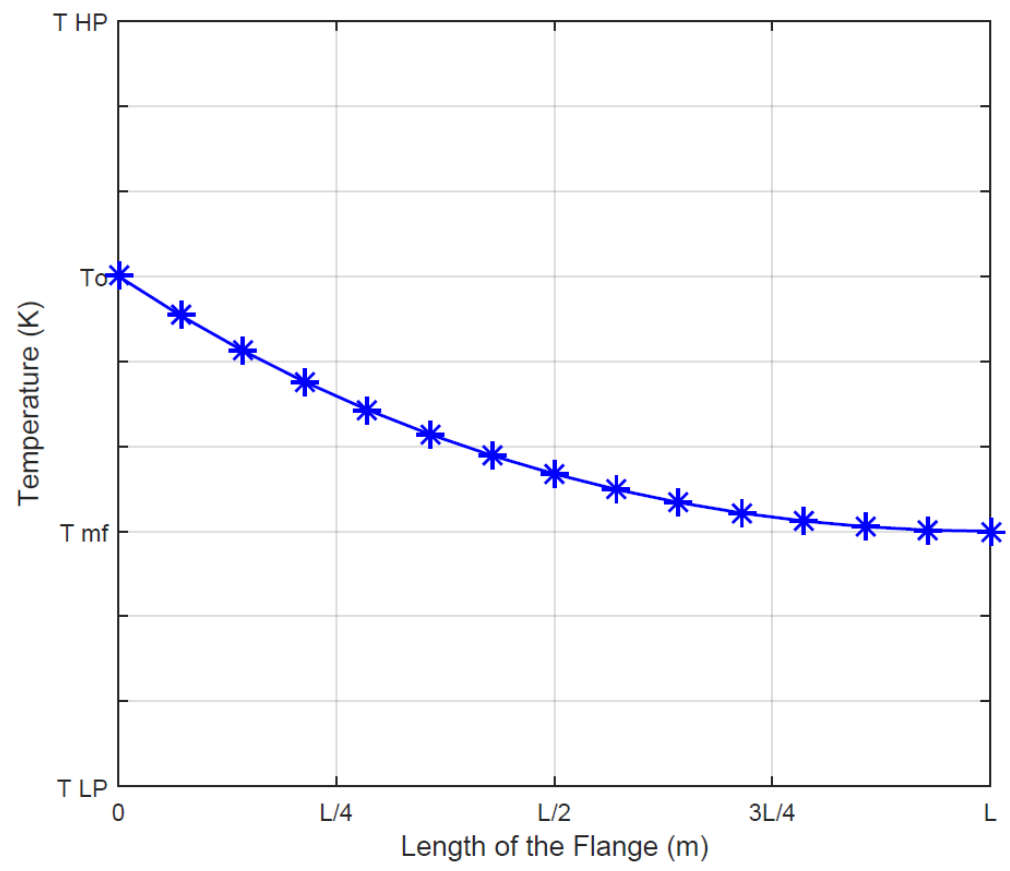

Figure 6. Temperature profile along the height of the flange

As explained earlier in Section 2, the air in each LP pipe is heated by the air flowing through the three different HP pipes bordering it. Due to the symmetry of the hexagonal mesh it is possible to assume that $1 / 6$ of the air in a HP pipe interacts with $1 / 3$ of the air in a LP pipe and that the mass of LP air contained in that $1 / 3$ of pipe does not interact with the remaining $2 / 3$ of LP air. Based on this assumption, the geometry can be further divided so that the calculations can focus only on a $1 / 12$ of a HP pipe and a $1 / 6$ of a LP pipe.

The heat flows (per unit length of $\mathrm{HX}$ ) inside this fraction of the geometry are calculated by means of the one dimensional conduction equation or the convection equation, depending on the case. Figure 7 shows the fraction of the geometry and the heat flows assumed for the modelling. 
$8 h=\frac{N u \cdot k_{\text {air }}}{\emptyset}$

$13 R e=\frac{\dot{m} \cdot \emptyset}{\mu \cdot A}$

$28 \nabla T=\frac{\dot{Q}}{\dot{m} \cdot(\psi) \cdot C_{p}}$ cross-section.

Where:

$$
\operatorname{Pr}=\frac{\mu \cdot C_{p}}{k_{\text {air }}}
$$

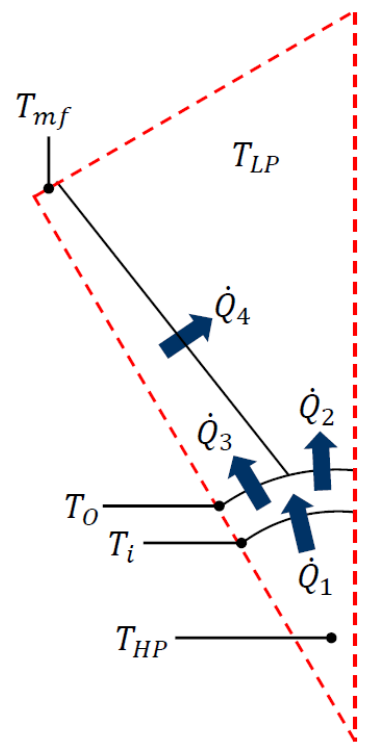

Figure 7. Segment of the geometry comprised by $1 / 12$ of the HP pipe and $1 / 6$ of the LP pipe

The heat transfer coefficients are calculated through Equation (19); it is important mentioning again that for the case of the LP stream an equivalent hydraulic diameter should be used as the pipe does not have a circular

$N u=0.023 \operatorname{Re}^{0.8} \operatorname{Pr}^{0.33}$

The specific heat capacity of the air $\left(C_{P}\right)$ is calculated by means the equation proposed by Lemmon et al. [29] while the dynamic viscosity $(\mu)$ and thermal conductivity $\left(k_{\text {air }}\right)$ are calculated through the Lemmon and Jacobsen equations [30].

If an energy balance in this section is not met, the values for $t_{L P}$ and $T_{O}$ are revised and calculations are repeated. At this point, the geometry has been completely characterized and the heat flows are known, thus it is possible to calculate the temperature gradient of the $\mathrm{HX}$ segment through Equation (23), where $\psi$ is the fraction of the pipe being analysed (1/12 in the case of HP pipes and 1/6 in the case of LP pipes).The exergy losses due to pressure drops through Equation (24), the exergy losses due to heat transfer by means of Equation (25), the total exergy losses (26) while the mean exergy transfer is given by Equation (8).

$$
B_{\Delta P}=(\psi) \cdot \dot{m} \cdot R \cdot T_{a m b} \cdot\left(\frac{\Delta P}{P}\right)
$$


$B_{L Q}=B_{H P}-B_{L P}=\dot{Q} \cdot\left(1-\frac{T_{a m b}}{T_{H P}}\right)-\dot{Q} \cdot\left(1-\frac{T_{a m b}}{T_{L P}}\right)$

$B_{\text {Loss }}=B_{L Q}+B_{\triangle H P}+B_{\triangle L P}$

If equation (5), which dictates the relationship between exergy loses due to pressure drops in both streams with respect to total exergy losses is not satisfied, the values for $\dot{m}_{H P}$ and $\dot{m}_{L P}$ are revised and the whole process is carried out again. After knowing the value of $\bar{B}$ it is possible to calculate the volume of material required per unit of exergy transfer, the minimization of which is the objective of the optimization since it is one of the main cost-driving factors.

\section{Analysis of results obtained for an $\mathrm{HX}$ segment}

A case study developed by means of the algorithm previously described is presented and thoroughly analysed in the current section. The material selected for the construction of the structure is a typical 316 stainless steel (one of the most widely used types); although pressure permitting, better thermal conductors as copper could be employed. As aforementioned, the geometry developed will be used as an air to air heat exchanger in which the low pressure stream will be at (or near) ambient pressure.

A number of designs corresponding to different values of $D$, going from 0.01 to $0.25 \mathrm{~m}$ were generated. This allows understanding the behaviour of different performance metrics of the $\mathrm{HX}$ as it is scaled up and selecting the configuration that attains the highest exergy transfer per unit volume.

Two case studies are analysed for average temperatures of $745 \mathrm{~K}$ and $400 \mathrm{~K}$. One of the envisioned applications for a $\mathrm{HX}$ of this kind are compressed air energy storage systems in which a high exergy efficiency of the components (i.e. small losses of work potential) are crucial. These systems produce streams of compressed air at pressures in the range of 5-7 MPa and temperature in the range of 770-800 K. A segment of $\mathrm{HX}$ operating at an average temperature of $745 \mathrm{~K}$ would be near the hot end of the device in such an application. The temperature of $400 \mathrm{~K}$ selected for second case study was selected (rather arbitrarily) with the aim of investigating how the different performance parameters vary with temperature.

The thermal conductivity of the stainless steel used for the structure is given by Equation (27). The parameters and values of the slow moving variables used for the two case studies are given in Table 1.

$K_{\text {wall }}=25.5+12.5 E^{-3} T_{\text {avg }}-8.33 E^{-6}\left(T_{\text {avg }}\right)^{2}$

It is noteworthy that the value of $110.6 \mathrm{MPa}$ defined in this study for the allowable stress $(S)$ of the material is in agreement with the recommended values by the ASME. According to the code B31.1 for pressure piping the average maximum allowable stress at a temperature of $755.4 \mathrm{~K}$ is $121.3 \mathrm{MPa}$, with a tolerance of $\pm 3.3 \%$ to account for variations in the composition of the 316-steel [31]. This value is well below the yield strength of the material for obvious safety reasons; in the pessimistic case when the maximum allowed stress is 117.3 $\mathrm{MPa}$, the value utilized for the calculations still falls within a safe region being $5.7 \%$ lower than the recommendation. It is important to bear in mind that the properties of the metal used may worsen to some degree from being deposited rather than continuously draw as in the standard manufacturing process of pipes; therefore it would recommendable to add an allowance for this. The value for $S$ was not changed for the calculations at the lower temperature of $400 \mathrm{~K}$, being approximately $16 \%$ below the maximum allowed for that case. 


\begin{tabular}{c|ll}
\hline & $\mathrm{W}$ & $0.97,0.98 \& 0.99$ \\
Slow Moving & $X$ & 1.0 \\
Variables & $Y$ & 0.5 \\
& $Z$ & 0.5 \\
\hline & $T_{\text {avg }}$ & $745 \mathrm{~K} \& 400 \mathrm{~K}$ \\
Air & $T_{a m b}$ & $290 \mathrm{~K}$ \\
Properties & $P_{H P}$ & $5 \mathrm{MPa}$ \\
& $P_{L P}$ & $101.325 \mathrm{kPa}$ \\
\hline \multirow{2}{*}{ Structure } & $K_{\text {wall }}$ & See Eq. $27(\mathrm{~W} / \mathrm{mK})$ \\
Properties & $S$ & $110.6 \mathrm{MPa}$ \\
& $\varepsilon / \varnothing$ & 0.005 \\
\hline
\end{tabular}

Figure 8 shows the variation of the volume of material required per unit of exergy transfer with respect to $D$ at different levels of exergy efficiency. The plot reveals two important facts: the first is that as $D$ increases more material for the body of the segment is needed per kW of exergy transfer; therefore the performance of the $\mathrm{HX}$ worsens. For $T_{\text {avg }}=745 \mathrm{~K}, D=0.25 \mathrm{~m}$ and $W=0.99$ a volume of $70.41 \mathrm{E}^{-3} \mathrm{~m}^{3}$ per kW of exergy transfer is needed while for a $D=0.01 \mathrm{~m}$ the volume needed per kW of exergy transfer, at the same exergy efficiency, decreases to $17.16 \mathrm{E}^{-5} \mathrm{~m}^{3}$.

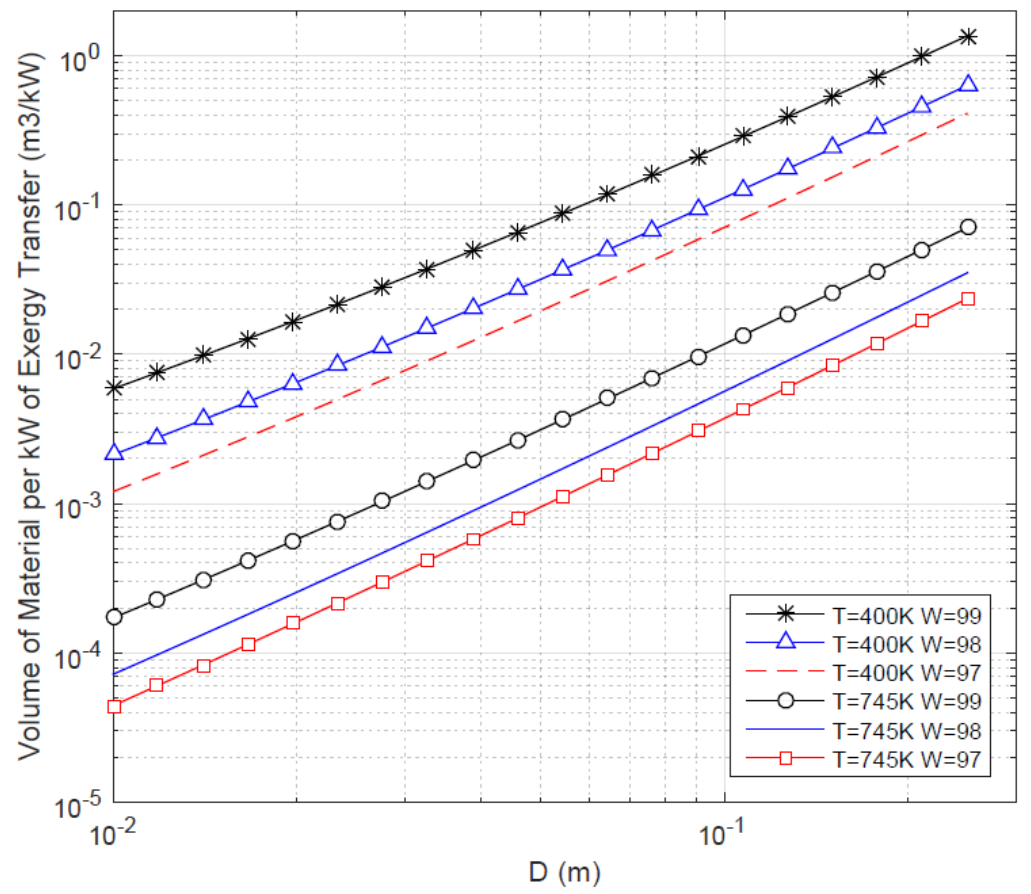

Figure 8. Volume of material per kW of exergy transfer for different values of $D$

Moreover, the average slope of the curves in Figure 8 is $1.949,1.922$ and 1.869 for $\mathrm{W}=0.97,0.98$ and .0 .99 respectively, at a temperature of $745 \mathrm{~K}$; while for a temperature of $400 \mathrm{~K}$ it is $1.69,1.769$ and 1.811 . This entails that the volume per $\mathrm{kW}$ of exergy transfer nearly quadruples if the characteristic dimension $D$ is doubled. This is in accordance with empirical conclusions from the HX industry which suggest that in general, smaller dimensions yield a better performance.

The second important fact is that as the level of exergy efficiency increases more volume of material is needed; i.e. a HX becomes (as expected) more expensive as it becomes more efficient. Additionally, it may be observed that the delta in volume from one value of $\mathrm{W}$ to another increases as $\mathrm{W}$ rises; however, it is not as large as expected. 
Figure 9 presents the variation of the $\dot{m}$ for different exergy efficiencies as the geometry is scaled up. The plot only shows $\dot{m}_{H P}$ as it has been established that $\dot{m}_{L P}$ needs to be half as much for having equivalent mass flow rates in both directions. The mass flow rates per pipe increase with $D$, as expected, because the geometry is growing. For $T_{\text {avg }}=745 \mathrm{~K}, D=0.01 \mathrm{~m}$ and $W=0.99$ a $\dot{m}_{H P}$ of $24.26 \mathrm{E}^{-5} \mathrm{~kg} / \mathrm{s}$ is needed while for a $D=$ $0.25 \mathrm{~m}$ and the same $W$ the $\dot{m}_{H P}$ needed increases to $11.79 \mathrm{E}^{-2} \mathrm{~kg} / \mathrm{s}$.

An interesting fact, however, is that the mass flow for lower exergy efficiencies are higher than those for higher exergy efficiencies. This occurs because as the geometry grows the $\Delta P$ in the pipes decrease; $\Delta P$ also decreases as $W$ increases. The foregoing means that higher $\dot{m}$ are required to satisfy Equation (5); in other words, the value defined for $Z$ forces the system to increase $\dot{m}$ so that more exergy is lost due to pressure drops and the proportion established by Equation (5) can be met.

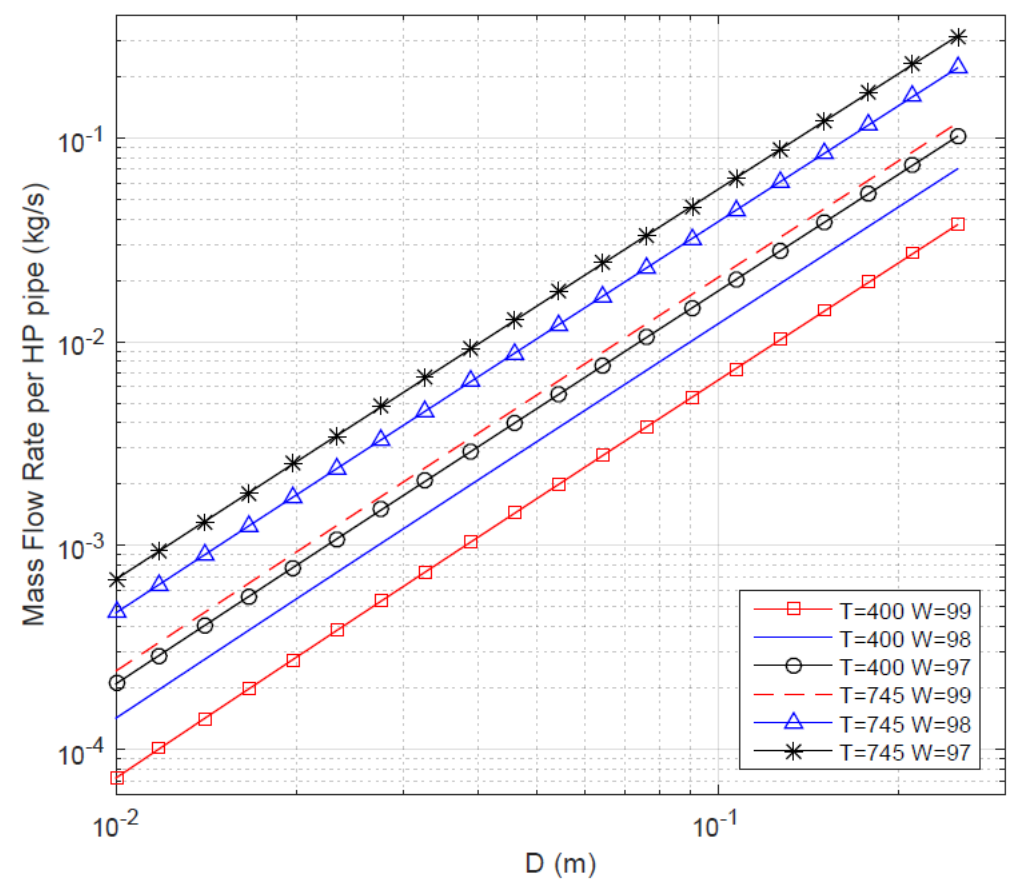

Figure 9. Mass flow rate per HP pipe for different values of $D$

Figures 10 and 11 show the behaviour of the velocities of both air streams with respect to $D$ for different levels of exergy efficiency at a $T_{\text {avg }}$ of 745 and $400 \mathrm{~K}$, respectively. As it may be observed, velocities are smaller for lower average temperatures. In both cases, velocities decrease as $D$ increases, despite increasing mass flow rates, due to the growth of the cross sectional area of the pipes.

Velocities of the streams decrease with increasing $W$ because pressure drops (shown in Figures 12 and 13) depend directly on them, so velocities have to be reduced in order to keep pressure-related exergy losses $\left(B_{\Delta P}\right)$ to a minimum and achieve higher exergy efficiencies.

Furthermore, it can be seen from figure 10 that the velocities of the LP stream for the 97 and $98 \%$ efficient designs are considerably high (>10 m/s), which renders nearly all designs for these efficiencies unusable for practical applications. 


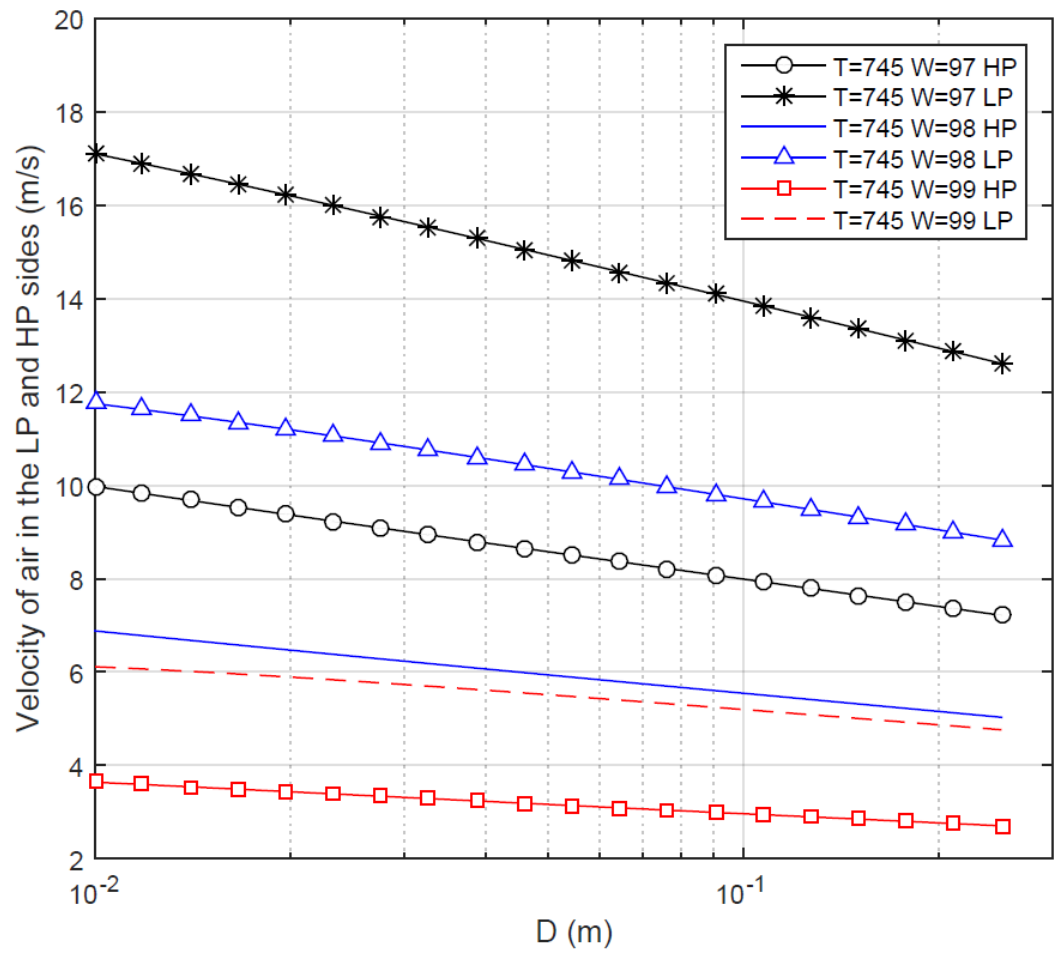

Figure 10. Air velocities in both streams of the $\mathrm{HX}$ for different values of $\mathrm{D}$ at a $\mathrm{T}_{\text {avg }}$ of $745 \mathrm{~K}$

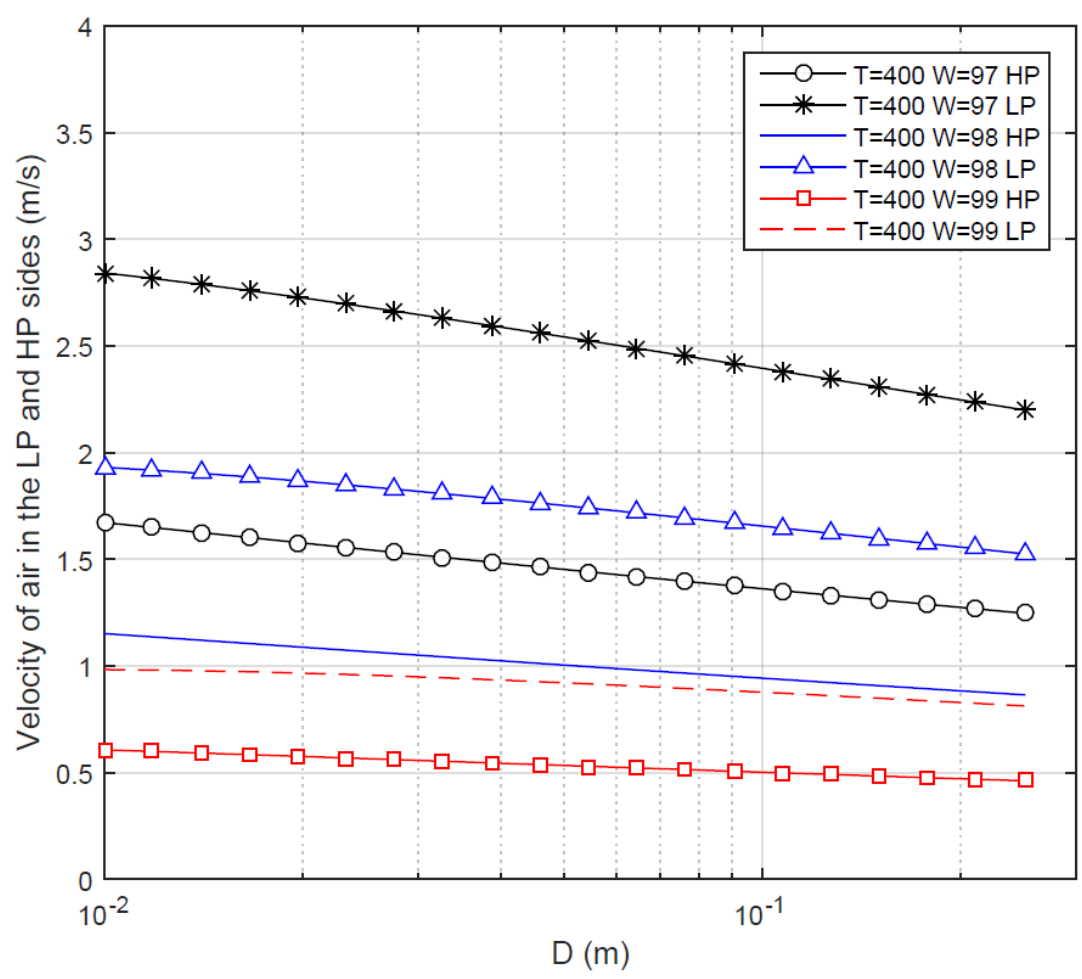

Figure 11. Air velocities in both streams of the $\mathrm{HX}$ for different values of $\mathrm{D}$ at a $\mathrm{T}_{\text {avg }}$ of $400 \mathrm{~K}$ 


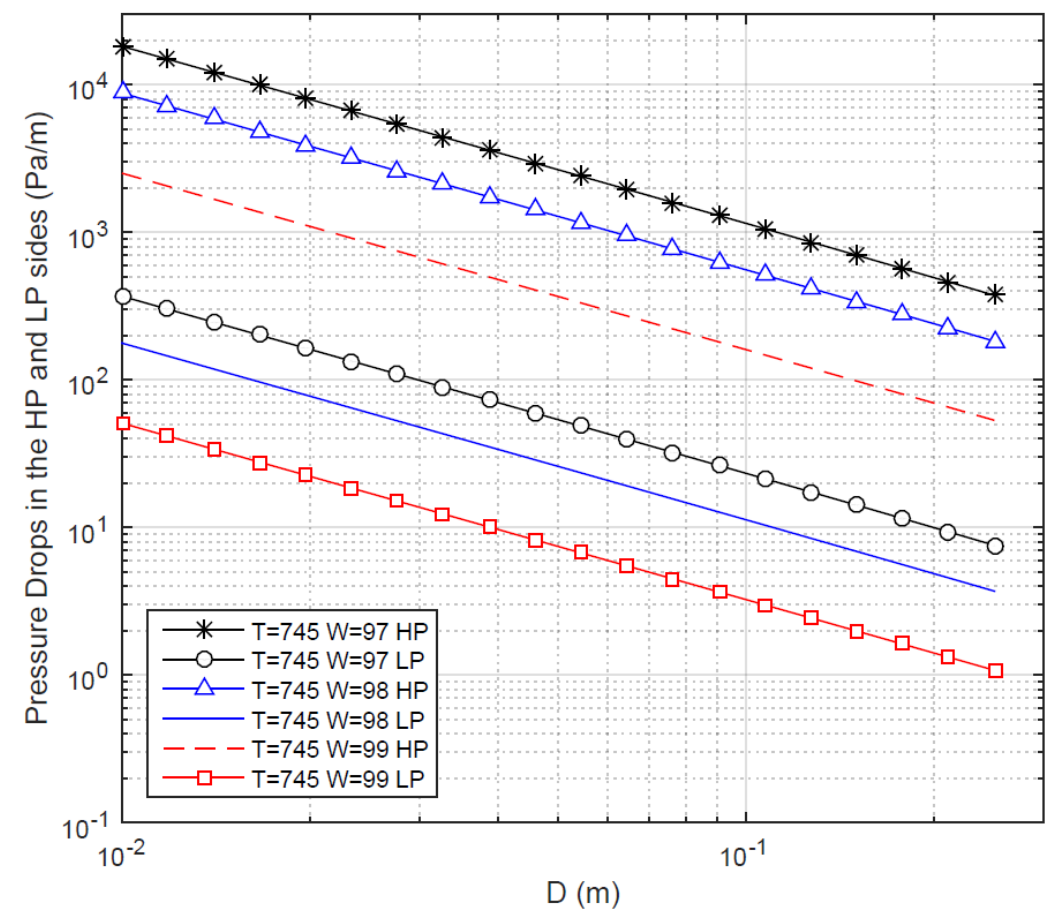

Figure 12. Pressure drops in both streams of the $H X$ for different values of $D$ at a $T_{\text {avg }}$ of $745 \mathrm{~K}$

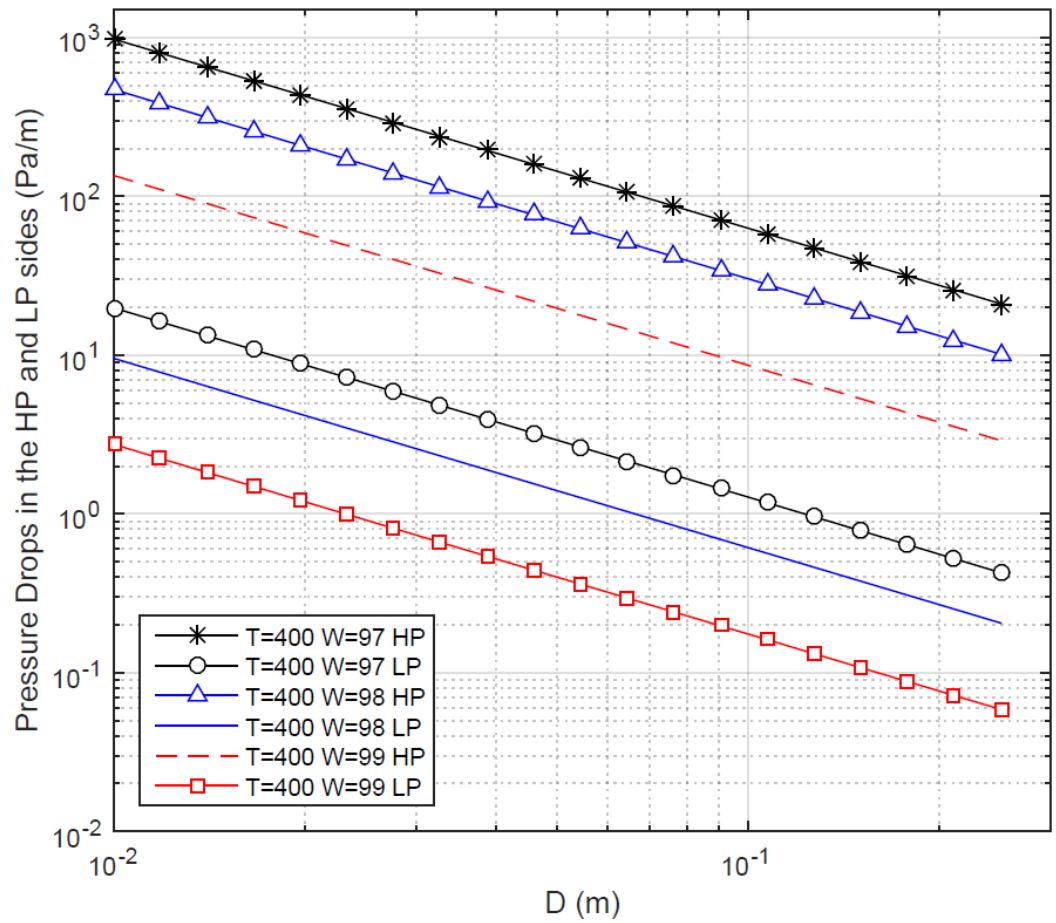

Figure 13. Pressure drops in both streams of the $H X$ for different values of $D$ at a $T_{\text {avg }}$ of $400 \mathrm{~K}$

Figure 14 shows the variation of the temperature gradient (temperature change of the streams per unit length) of the segment with respect to $D$ at different levels of exergy efficiency. This parameter is of great importance as it provides information regarding the length of the HX (although ideally the length segment is small). The temperature gradient decreases with increasing $D$ because $\dot{m}$ increase. For $T_{\text {avg }}=745 \mathrm{~K}, D=$ $0.25 \mathrm{~m}$ and $W=0.99$ a $\nabla T$ of $0.5354 \mathrm{~K} / \mathrm{m}$ is observed while a $\nabla T$ of $25.25 \mathrm{~K} / \mathrm{m}$ is achieved for $D=0.01 \mathrm{~m}$ and $W=0.99$.

A higher temperature gradient is observed for lower efficiencies due to a larger heat transfer resultant from increased mass flow rates and heat transfer coefficients. This is in agreement with the results presented in 
figure 8 , which states that more volume of material is required per kW of exergy transfer as the exergy efficiency increases.

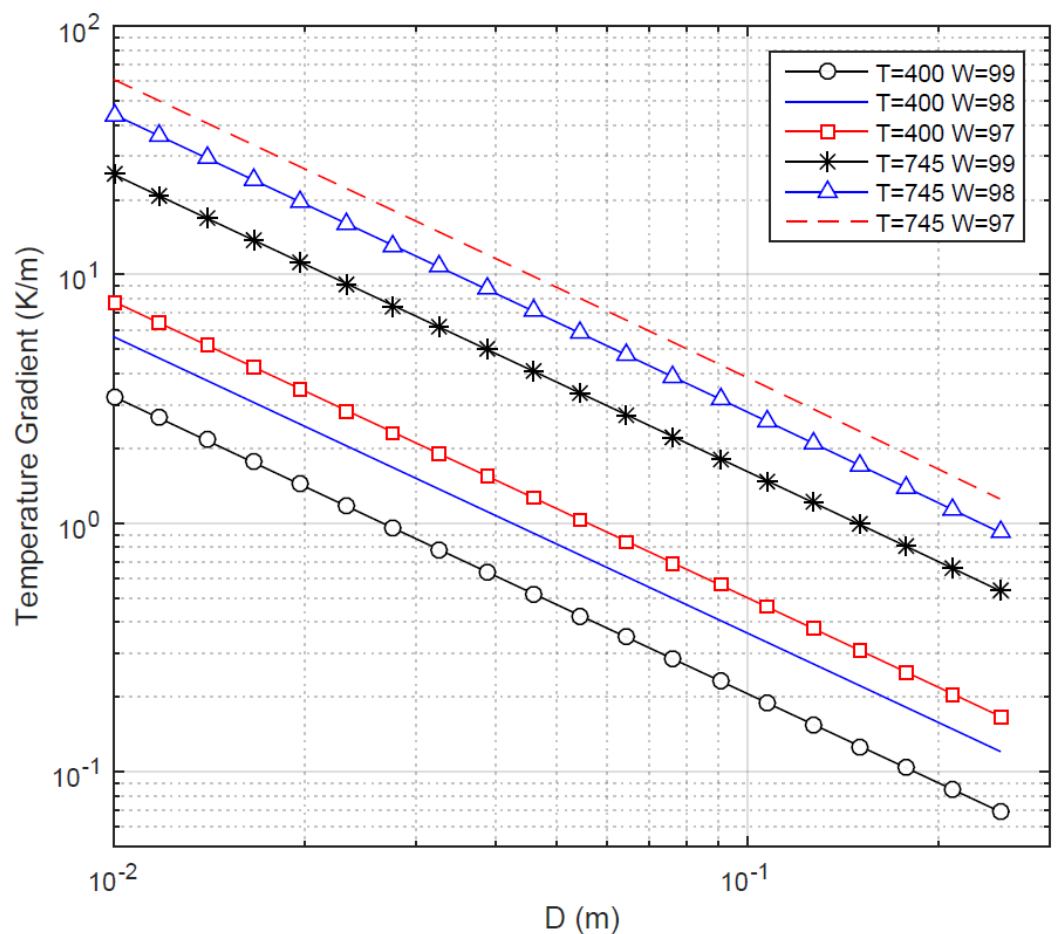

Figure 14. Temperature gradient of the streams for different values of $D$

Figures 15 and 16 provide information about the geometrical proportions of the cross sectional area designed. The fraction of the outer perimeter of the HP pipes that is covered by flanges $(\lambda)$ is shown in figure 15 , while the ratio between cross sectional areas of the HP and LP pipes $\left(A_{r}\right)$ is shown in figure 16 . $\lambda$ increases with $D$, which contributes to the larger volume per $\mathrm{kW}$ of exergy transfer observed for larger values of $D$. For a $T_{\text {avg }}=$ $745 K, D=0.01 \mathrm{~m}$ and $W=0.99$ a $\lambda$ of 0.027 is observed while $\lambda$ increases to 0.285 for $D=0.025 \mathrm{~m}$ and $W=0.99$. It should also be noted that for any given value of $D$, the HP pipes are less covered by flanges as the efficiency of the $\mathrm{HX}$ increases.

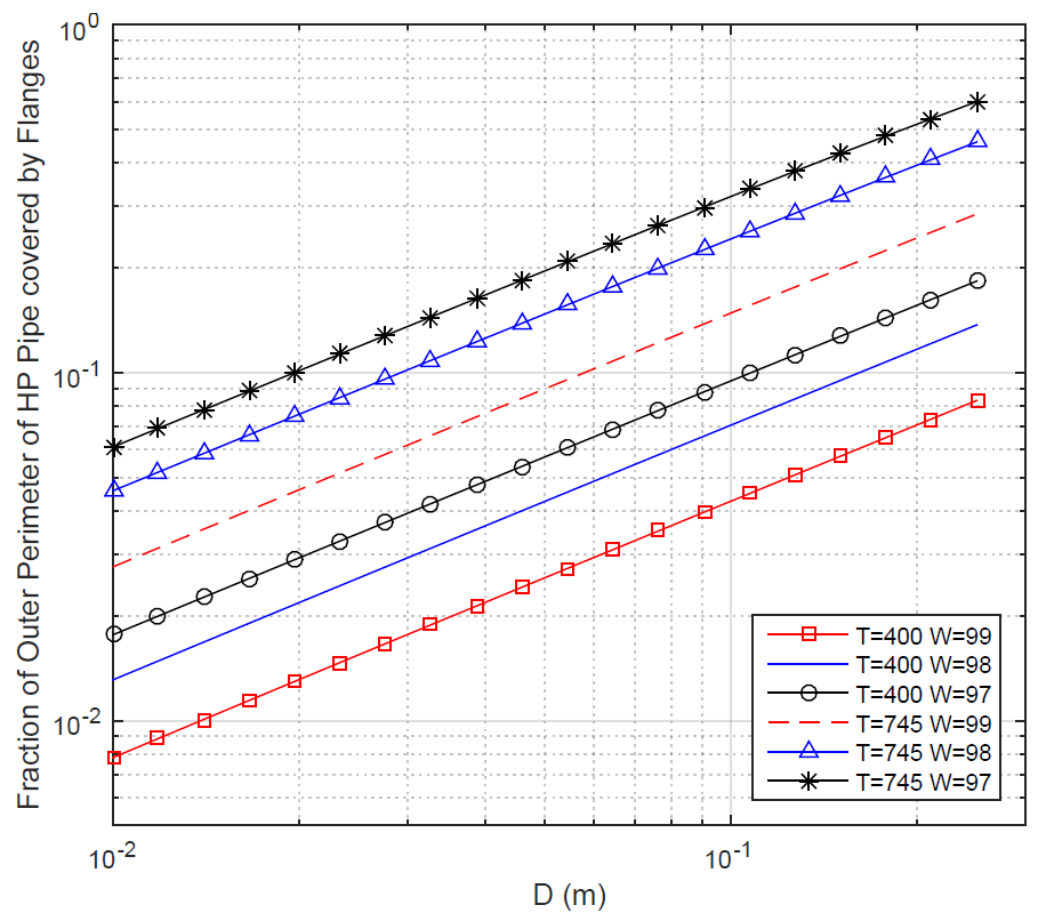

Figure 15. Fraction of outer perimeter of an HP pipe covered by flanges for different values of $D$ 
$A_{r}$ increases with $\mathrm{D}$, meaning that the HP pipes grow faster in comparison to LP pipes; however, the increase rate of this ratio decreases as $\mathrm{D}$ becomes larger. For a $T_{\text {avg }}=745 \mathrm{~K}, D=0.01 \mathrm{~m}$ and $W=0.99$ an $A_{r}$ of 0.0686 is observed while for a $D=0.25 \mathrm{~m}$ and $W=0.99$ this value increases to 0.0719 .

For any given $D$ this ratio is smaller for the higher efficiency designs because for achieving higher exergy efficiencies exergy losses due to pressure drops are minimized by reducing mass flow rates, which translates into smaller radii of the HP pipes and consequently a smaller aspect ratio.

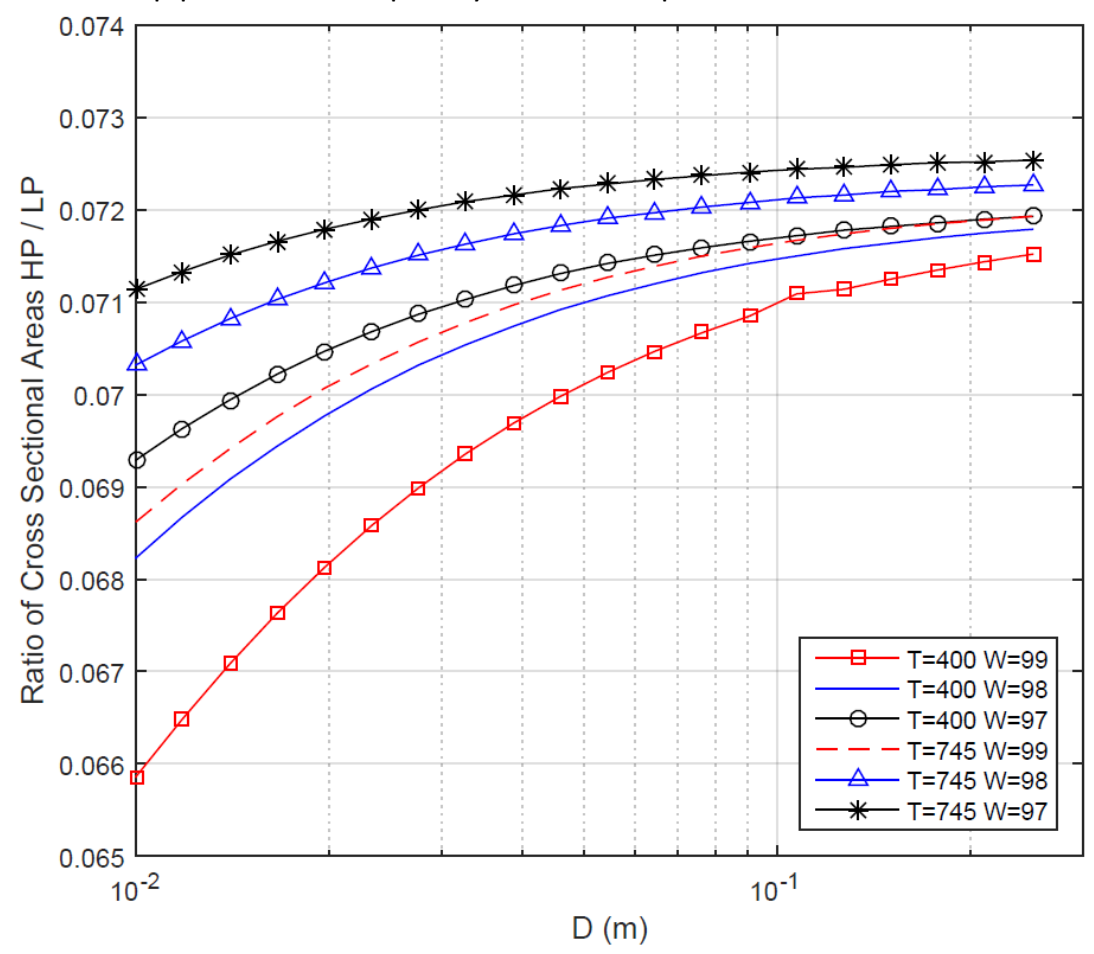

Figure 16. Ratio of cross sectional areas (HP/LP) for different values of $D$.

\subsection{Fine tuning of slow moving variables}

One of the key benefits offered by the slow moving variables is the ability to carry out an optimization process through their fine tuning to improve the results obtained from the mathematical model.

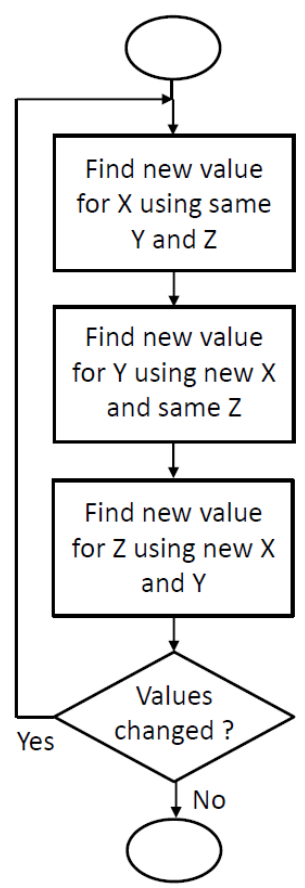


A)

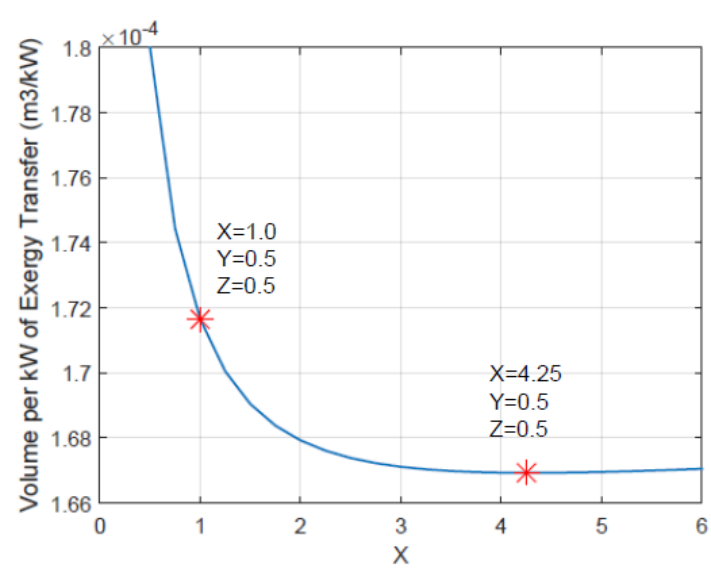

C)

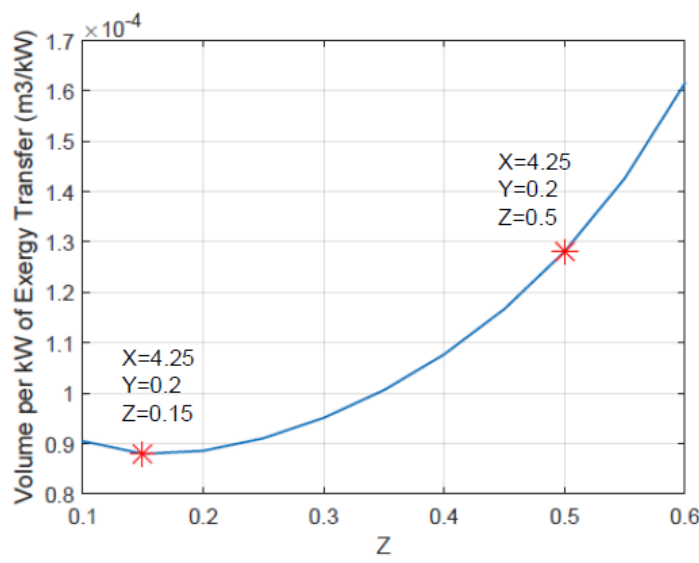

B)

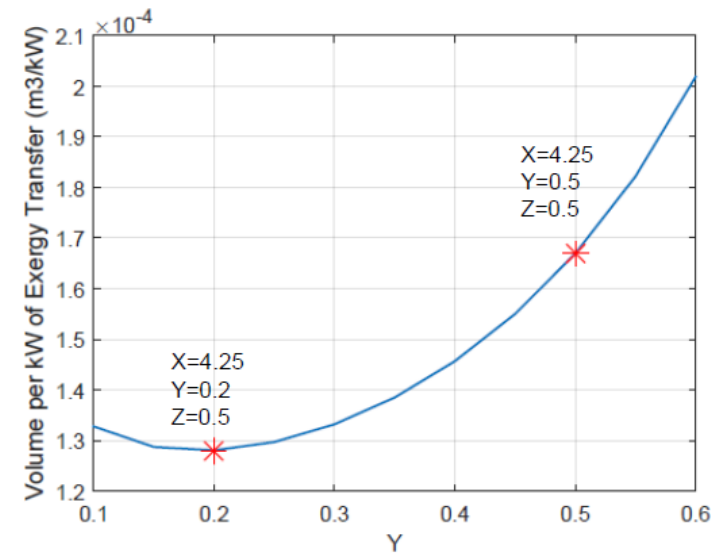

D)

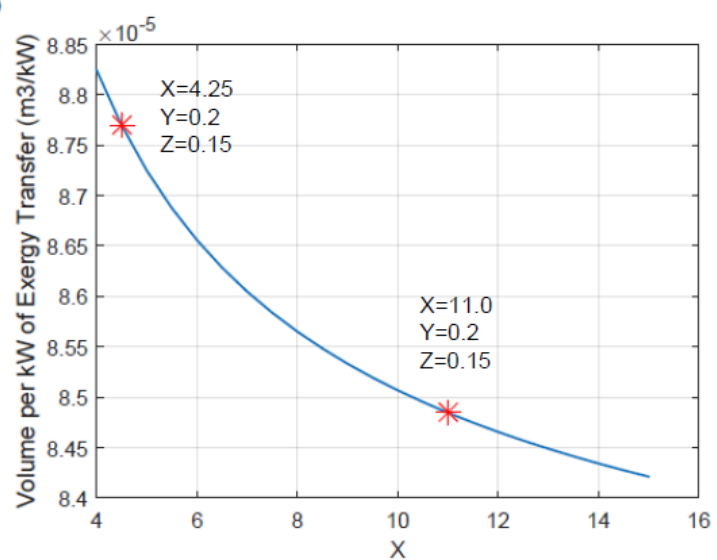

Figure 18. Reduction of $V / \bar{B}$ through the tuning of the slow moving variables 
The newfound values for the slow moving variables are used as starting point for a second iteration, shown in figure 18 (d). Interestingly, the volume of material per unit of exergy transfer decreases continuously as $X$ increases until reaching very small values. After $X=11$ the $L P$ stream presents a very small Reynolds number for being considered as a turbulent flow $(<4000)$ [33] due to a considerable decrease in the velocity of the air. In order to maintain a healthy heat transfer in the pipes having a turbulent flow is desired, therefore the sweep is stopped at $X=11$. Subsequent sweeps were made for $Y$ and $Z$ (not shown in the figures) and no change was found in their values, therefore the optimization loop was concluded.

The final design for the cross-sectional area of the segment of the HX is obtained after the slow moving variables have been fine-tuned. The geometric parameters and relevant performance metrics of the design generated for the case study are given in Table 2.

Table 2. Geometric parameters and performance metrics of the final HX segment design

\begin{tabular}{|c|c|c|c|}
\hline Category & Parameter & Value & \\
\hline \multirow{7}{*}{ Geometric } & $D$ & 0.01 & $m$ \\
\hline & $r_{H P}$ & $5.701 \mathrm{E}^{-4}$ & $\mathrm{~m}$ \\
\hline & $t_{H P}$ & $2.699 \mathrm{E}^{-5}$ & $\mathrm{~m}$ \\
\hline & $t_{L P}$ & $3.959 \mathrm{E}^{-6}$ & $\mathrm{~m}$ \\
\hline & $L$ & $4.403 \mathrm{E}^{-3}$ & $\mathrm{~m}$ \\
\hline & $A_{r}$ & 0.0238 & \\
\hline & $\lambda$ & 0.006 & \\
\hline \multirow{12}{*}{ Operational } & $X$ & 11.0 & \\
\hline & $Y$ & 0.2 & \\
\hline & $Z$ & 0.15 & \\
\hline & $P_{H P}$ & 5.0 & $\mathrm{MPa}$ \\
\hline & $P_{L P}$ & 101.325 & $\mathrm{kPa}$ \\
\hline & $T_{a v g}$ & 745 & $\mathrm{~K}$ \\
\hline & $T_{H P}$ & 749.967 & $\mathrm{~K}$ \\
\hline & $T_{L P}$ & 740.032 & $\mathrm{~K}$ \\
\hline & $\dot{m}_{H P}$ & $6.494 \mathrm{E}^{-5}$ & $\mathrm{Kg} / \mathrm{s}$ \\
\hline & $\dot{m}_{L P}$ & $3.247 \mathrm{E}^{-5}$ & $\mathrm{Kg} / \mathrm{s}$ \\
\hline & $U_{H P}$ & 2.739 & $\mathrm{~m} / \mathrm{s}$ \\
\hline & $U_{L P}$ & 1.593 & $\mathrm{~m} / \mathrm{s}$ \\
\hline \multirow{5}{*}{ Performance } & $W$ & 0.99 & \\
\hline & $\Delta P_{H P}$ & 2423.7856 & $\mathrm{~Pa} / \mathrm{m}$ \\
\hline & $\Delta P_{L P}$ & 4.4649 & $\mathrm{~Pa} / \mathrm{m}$ \\
\hline & $\nabla T$ & 44.4141 & $\mathrm{~K} / \mathrm{m}$ \\
\hline & $V / \bar{B}$ & $8.485 \mathrm{E}^{-5}$ & $\mathrm{~m}^{3} / \mathrm{kW}$ \\
\hline
\end{tabular}

A volume of $8.485 \mathrm{E}^{-5} \mathrm{~m}^{3}$ of material per kW of exergy transfer with an exergy efficiency of $99 \%$ is achieved. For reference, a conventional shell and tube heat exchanger that operates between 820 and $350 \mathrm{~K}$ on the tube side with a pressure of $7 \mathrm{MPa}$ requires of approximately $14.917 \mathrm{E}^{-3} \mathrm{~m}^{3}$ per KW of exergy transfer with an efficiency of $95 \%$. The volume obtained at the end of the one-factor at a time optimization translates roughly into a cost of $53 € / \mathrm{kW}$ (due to material only) considering an approximate cost of $80 € / \mathrm{kg}$ for the steel powder for laser manufacturing [34]. Although the material used represents a large share of the total cost of a 3D printed part; additional fabrication costs such as labour (e.g. pre-processing of the job) and-specially- machine time are by no means negligible. 
The complexity of the component affects-as expected-the fabrication time. Nevertheless, the current costing methods used for the fabrication of one-off and short run components by means of standard additive manufacturing equipment are based on pre-established rates per unit volume that have already factored in the additional fabrication costs aforementioned; so the intricacy of the design does not have a real impact on the end cost of the component. It is noteworthy that a further cost reduction can be achieved for hollow or holey designs that allow different components to be built simultaneously within their void spaces thus making a more efficient use of machine's running time.

The commonly found additive manufacturing equipment, considered nowadays as standard, has an average lower limit for wall thicknesses of one to two tenths of a millimetre, which would render most of the designs evaluated in the study as non-manufacturable. However the capabilities of the machinery are being enhanced at a rapid pace and companies such as nanoscribe [35] are already capable of fabricating complex crystal-like lattices in a micro-scale. Designs such as those herein presented might not be cost-effective presently for applications in which a very high exergy efficiency is not the top priority because the use of state-of-the-art equipment entails an increased cost. Nevertheless, both, material and indirect costs are expected to decrease as additive-manufacturing technologies mature and their capabilities are further developed.

It is important to emphasize that the design analysed as a case study is just an example used to demonstrate the premise that it is possible to create designs for heat exchangers that are highly exergy-efficient and require a very small volume of material (hence could be very cheap) if the constrains imposed by the limitations of traditional manufacturing methods are set aside.

\section{Concluding Remarks}

Diverse new manufacturing techniques, such as additive manufacturing, have been developed in recent years; these methods allow the fabrication of complex designs that could not be built through traditional methods or would not be cost-effective.

A design for the cross-sectional area of an air to air heat exchanger based on an hexagonal mesh has been proposed with which a significant volume (and ultimately cost) reduction per unit of exergy transfer can be attained. This geometric arrangement would be highly impractical to manufacture in a conventional way but could be built relatively easily by means of modern techniques.

A segment of the heat exchanger that will work at an average temperature of $745 \mathrm{~K}$ was designed and optimized and a volume of steel as low as $84.846 \mathrm{~cm}^{3}$ per $\mathrm{kW}$ of exergy transfer at a $99 \%$ exergy efficiency was obtained. Such geometry can be fabricated currently at competitive costs; and a further reduction in cost is expected as the new manufacturing methods mature. The design proposed is not only a reasonable structure for a heat exchanger at small scales but it approaches an optimum; however, partly due to space limitations on the work beds of additive manufacturing machines, it is considered to be not particularly well suited for larger scales.

The study revealed a very important fact. The volume per kW of exergy transfer, which is one of the main costdriving factors, increase in a nearly quadratic proportion with respect to the characteristic dimension (distance between centres of high pressure pipes) of the heat exchanger. This means that if the geometry is scaled up by doubling the distance between HP pipes, the volume of material per kW of exergy transfer will not be doubled; as intuition would suggest, but it will nearly quadruple.

This observation may be true for other types of heat exchangers and with further analysis it could be regarded as a rule of thumb. It strongly suggests that the design of heat exchangers should shift towards smaller scales as much as manufacturing methods allow to substantially increase performance and reduce costs. 


\section{Acknowledgements}

This work has been developed within the framework of the NexGen-TEST project; which has been made possible by a collaborative research initiative between the UK Engineering and Physical Sciences Research Council (EPSRC) and the National Natural Science Foundation of China (NSFC).

\section{References}

[1] Thulukkanam K. 2013. Heat exchanger design handbook, CRC Press, Florida, USA, pp. 1-15.

[2] Hadidi A, Nazari A. 2013. Design and economic optimization of shell-and-tube heat exchangers using biogeography-based (BBO) algorithm. Appl. Therm. Eng.51, 1263-1272.

[3] Caputo AC, Pelagagge PM, Salini P. 2015. Heat exchanger optimized design compared with installed industrial solutions. Appl. Therm. Eng. 87,371-380.

[4] Sanaye S, Hajabdollahi H.2010. Multi-objective optimization of shell and tube heat exchangers. Appl. Therm. Eng.30,1937-1945.

[5]Sanaye S, Hajabdollahi H.2010. Thermal-economic multi-objective optimization of plate fin heat exchanger using genetic algorithm. Appl. Energy. 87:1893-902.

[6] Hajabdollahi H, Tahani M, Fard MHS. 2011. CFD modeling and multi-objective optimization of compact heat exchanger using CAN method. Appl. Therm. Eng.31,2597-604.

[7] Najafi H, Najafi B, Hoseinpoori P.2011.Energy and cost optimization of a plate and fin heat exchanger using genetic algorithm. Appl. Therm. Eng.31,1839-47.

[8] Fettaka S,Thibault J, Gupta Y. 2013.Design of shell-and-tube heat exchangers using multiobjective optimization. Int. J. Heat Mass Tran.60,343-354.

[9] Patel VK, Rao RV. 2010. Design optimization of shell-and-tube heat exchanger using particle swarm optimization technique. Appl. Therm. Eng.30,1417-1425.

[10] Patel VK, Rao RV.2010. Thermodynamic optimization of cross flow plate-fin heat exchanger using a particle swarm optimization algorithm. Int. J. Therm. Sci. 49,1712-21.

[11] Mariani VC, Duck ARK, Guerra FA, Coelho LdS, Rao RV. 2012. A chaotic quantum-behaved particle swarm approach applied to optimization of heat exchangers. Appl. Therm. Eng.42,119-128.

[12] Sadeghzadeh H, Ehyaei MA, Rosen MA. 2015. Techno-economic optimization of a shell and tube heat exchanger by genetic and particle swarm algorithms. Energy Convers. Manag.93, 84-91.

[13] Turgut OE. 2015. Hybrid chaotic quantum behaved particle swarm optimization algorithm for thermal design of plate fin heat exchangers. Appl. Math. Model. 40,50-69.

[14] Hadidi A, Hadidi M, Nazari A. 2013. A new design approach for shell-and-tube heat exchangers using imperialist competitive algorithm (ICA) from economic point of view. Energy Convers. Manage.67,66-74.

[15] Yousefi M, Enayatifar R, Darus AN, Abdullah AH.2013. Optimization of plate-fin heat exchangers by an improved harmony search algorithm. Appl. Therm. Eng.50, 877-885.

[16]Wang Z, Li Y. 2015. Irreversibility analysis for optimization design of plate fin heat exchangers using a multi-objective cuckoo search algorithm. Energ. Conv. Manage. 101,126-135.

[17] Asadi M, Song Y, Sunden B, Xie G.2014. Economic optimization design of shell and- tube heat exchangers by a cuckoo-search-algorithm. Appl. Therm. Eng.73, 1032-1040.

[18] Hultmann HV, Keller P, Morais MF, Mariani VC, Dos Santos L, Rao RV. 2016. Design of heat exchangers using a novel multiobjective free search differential evolution paradigm. Appl. Therm. Eng. 94, 170-177

[19]Sahin AS, Kilic B, Kilic U. 2011. Design and economic optimization of shell and tube heat exchangers using Artificial Bee Colony (ABC) algorithm. Energ. Conv. Manage. 52, 3356-3362.

[20] Rao RV, Patel V. 2013. Multi-objective optimization of heat exchangers using a modified teachinglearning-based optimization algorithm, Appl. Math. Model. 37, 1147-1162.

[21] Patel V, Savsani V. 2014. Optimization of a plate-fin heat exchanger design through an improved multiobjective teaching-learning based optimization (MO-ITLBO) algorithm. Chem. Eng. Res. Des.92, 2371-2382.

[22]Mohanty DK. 2016. Application of firefly algorithm for design optimization of a shell and tube heat exchanger from economic point of view. Int. J.Therm. Sci. 102, 228-238. 
[23] Stewart M. Lewis OT. 2013. Heat exchanger Equipment field manual: Common operating problems and practical solutions. Gulf Professional Publishing. Oxford, UK. pp. 16-17.

[24] Haaland, S. 1983. Simple and Explicit Formulas for the Friction Factor in Turbulent flow. Journal of Fluids Engineering. 103,89-90.

5 [25] Fox W, Pritchard P, McDonald A. 2010. Introduction to Fluid Mechanics. John Wiley \& Sons,. New Jersey, 6 USA. pp.754.

7 [26] Shashi EM (2011) Pipe Strength and Wall Thickness in E. Shashi Menon(Ed.) Pipeline Planning and

8 Construction Field Manual (pp.105-121). Oxford, UK. Gulf Professional Publishing

9 [27] Kakaç S, Yener Y, Pramuanjaroenkij A. 2014. Convective Heat transfer. CRC Press, Florida, USA. pp. 157.

10 [28] Janna WS. 2009. Engineering Heat Transfer. CRC Press, Florida, USA. pp. 2-44.

[29] Lemmon EW, Jabosen RT, Penoncello SG, Friend DG. 2000. Thermodynamic properties of air and mixtures of nitrogen, argon and oxygen from 60 to $2000 \mathrm{~K}$ at pressures to $2000 \mathrm{MPa}$. J. Phys, Chem. Ref. Data. 29, 331385.

[30] Lemmon EW, Jacobsen RT. 2004. Viscosity and thermal conductivity equations for nitrogen, oxygen, argon and air. Int. J. Thermophys. 25,21-69.

[31]American Society of Mechanical Engineers, 2001. ASME code for pressure piping B31: An American national standard. New York, USA. Pp 140-141.

[32] Wahid Z, Nadir N. 2013. Improvement of One Factor at a Time through Design of Experiments. World Applied Sciences Journal. 21,56-61.

[33] Bertsche D, Knipper P, Wetzel T. 2016. Experimental investigation on heat transfer in laminar, transitional and turbulent circular pipe flow. Int J Heat Mass Tran. 95, 1008-1018.

[34]Piili H, Happonen A, Väistö T, Venkataramanan V, Partanen J, Salminen A. 2015. Cost Estimation of Laser Additive Manufacturing of Stainless Steel. Physics Procedia.78, 388 - 396.

[35]"Additive Manufacturing - Nanoscribe Gmbh". Nanoscribe.de. N.p., 2016. Web. 9 Oct. 2016.

25

26

27

28

29

30

31

32

33

34

35 


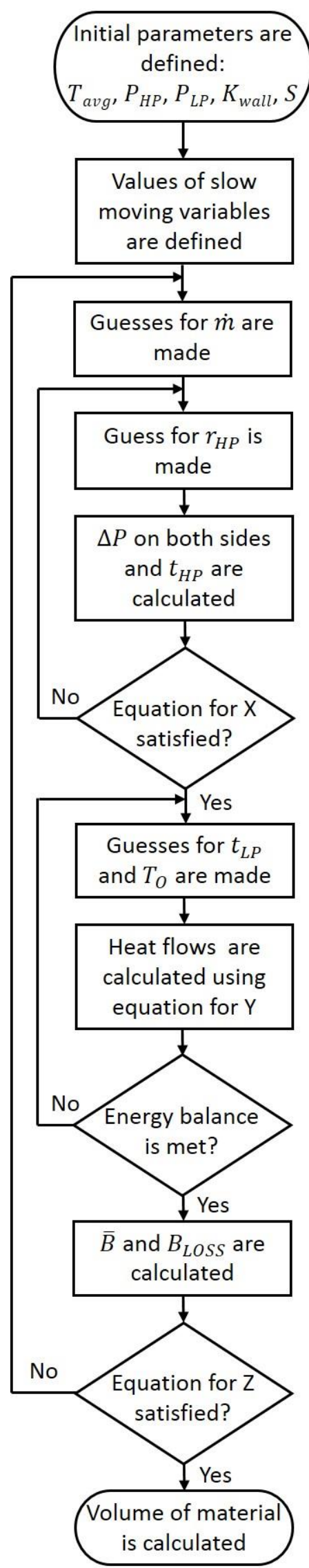

